\title{
POSTEMERGENCE GROWTH OF THE OVARIAN FOLLICLES OF AEDES AEGYPTI
}

\author{
H. H. Hagedorn, Sarah Turner, E. A. Hagedorn, David Pontecorvo, \\ Paula Greendaum, Douglass Pfeiffer, Geoffrey Wheelock, and T. R. Flanagan \\ Department of Entomology, University of Massachusetts, Amherst, MA. 01002, U.S.A.
}

(Received 21 June 1976; Revised 18 August 1976)

\begin{abstract}
Growth of the ultimate follicle to the resting stage in Aedes aegypti is linear and reaches maximum development about $60 \mathrm{hr}$ after emergence. Decapitations and ligations at various times after emergence indicate that growth of the follicles is under the control of factors from the head and thorax. Release of head factor occurs within one day after emergence and is relatively sudden. The thoracic factor is released gradually over a 2 to 3 day period. Near normal growth of follicles in isolated abdomens after topical application of juvenile hormone (JH) indicates that the thoracic factor is $\mathrm{JH}$ from the corpora allata and demonstrates the feasibility of using this system as a $\mathrm{JH}$ assay. When ecdysone was injected simultaneously with $\mathrm{JH}$ the follicles failed to grow.
\end{abstract}

\section{INTRODUCTION}

THE CORPORA allata is an important hormonal stimulus for egg maturation in many insects with the exception of some Lepidoptera and Diptera (review by DOANE, 1973). In the female mosquito allatectomy does not prevent egg maturation if the operation is performed 3 days after emergence. If the animals are allatectomized at emergence, however, egg development is arrested (LEA, 1969). Similar results have recently been described for Musca domestica (LEA, 1975).

In Aedes aegypti the corpora allata stimulates previtellogenic growth of the oöcytes (GWADZ and SPELMAN, 1973). In the newly emerged adult each ovariole consists of a germarium and a follicle which contains eight cells surrounded by a layer of follicle cells. At this time the oöcyte is not distinguishable from the seven nurse cells (Clements, 1963). By the third day after emergence the first, or ultimate, follicle in each ovariole is larger and the oöcyte can be easily distinguished. A second follicle, the penultimate, has also appeared but the oöcyte and nurse cells remain undifferentiated. The ultimate follicle at this time is said to be in a resting stage (corresponding to Stage IIb, Clements, 1963). GWADZ and SPIELMaN (1973) showed that the growth of the ultimate follicle to the resting stage is under the control of the juvenile hormone (JH) from the corpora allata (CA). In anautogenous mosquitoes, such as $A$. aegypti, the ultimate follicle remains in the resting stage until the female takes a blood meal. The blood meal triggers vitellogenic growth of the ultimate follicle and production of mature eggs (HAGEDORN, 1974). At the same time the next follicle (the penultimate follicle) grows to reach the resting stage. Gwadz and Spielman also showed that the growth of the penultimate follicle after a blood meal was under the control of the CA.
The present experiments were designed to determine the kinetics of how hormones affect the postemergence growth of the ovarian follicles to the resting stage. We also found that a bioassay for $\mathrm{JH}$ could be based on this growth, and that ecdysone inhibited growth.

\section{MATERIALS AND METHODS}

Mosquitoes were reared in plastic trays $(19 \times 26 \mathrm{~cm})$ holding $450 \mathrm{ml}$ of water and 200 larvae each. The food was a 50:50 mixture of non-clouding fish food and vitamin supplemented breakfast cereal. The temperature was maintained at $27.5^{\circ} \mathrm{C}$. Dissections were performed in Aedes saline (Table 1) and the length of 10 follicles from each of 10 animals was measured immediately using an ocular micrometer.

Operations were performed by trying a fine thread at either the neck or the base of the abdomen and removing the anterior portion. The wound was sealed with paraffin. Tying the thread at the neck will be termed 'decapitation'. Tying the thread at the base of the abdomen produces isolated abdomens and will

Table 1. Aedes saline modified from VARMA and PUDNEY (1969)

\begin{tabular}{lc}
\hline & $\mathrm{mM}$ \\
\hline $\mathrm{MgCl}_{2} \cdot 6 \mathrm{H}_{2} \mathrm{O}$ & 0.6 \\
$\mathrm{KCl}$ & 4.0 \\
$\mathrm{NaHCO}$ & 1.8 \\
$\mathrm{NaCl}$ & 150.0 \\
$\mathrm{HEPES}$ & 25.0 \\
$\mathrm{CaCl}_{2} \cdot 2 \mathrm{H}_{2} \mathrm{O}^{*}$ & 1.7 \\
\hline * Calcium is added after the $\mathrm{pH}$ is \\
adjusted to 7.0 with $\mathrm{NaOH}$.
\end{tabular}




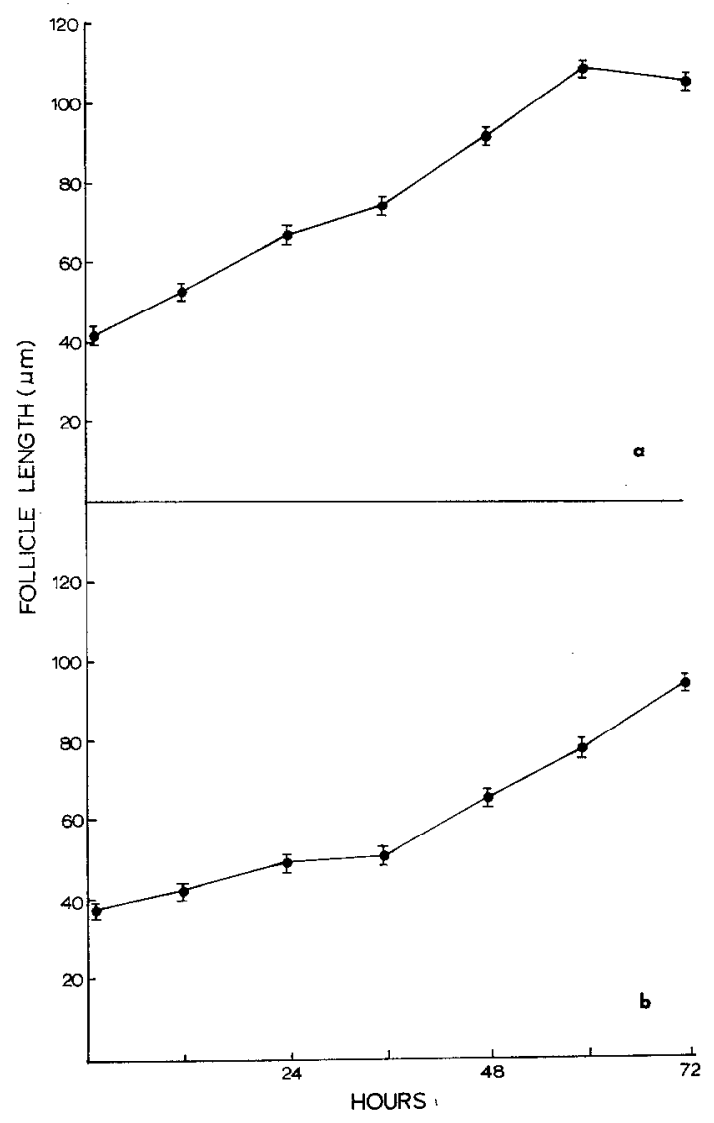

Fig. 1. Growth of the ultimate follicle after emergence (a) and penultimate follicle after a blood meal (b). Means are given \pm standard error.

be termed 'ligation' for convenience. Operated animals were maintained for three days at $27.5^{\circ} \mathrm{C}$ in a humidified chamber and were sprayed daily with a fine mist of water.

Animals to be used for the juvenile hormone assay were ligated within $30 \mathrm{~min}$ after emergence. The wound was sealed with melted paraffin and the abdomens were attached to the edge of a strip of parafilm in groups of $12 . \mathrm{C}_{18}$ juvenile hormone (mixture of isomers, Eco Control, Cambridge, Massachusetts) was topically applied in $0.5 \mu \mathrm{l}$ of acetone. The abdomens were then hung in a humidified chamber maintained at $27^{\circ} \mathrm{C}$ and sprayed daily with a fine mist of water. Sixty hours later the ovaries were removed and the follicle length was mcasurcd.

\section{RESULTS AND DISCUSSION}

We first examined the kinetics of follicle growth after emergence and after a blood meal (Fig. 1). Growth of the ultimate follicle after emergence is linear and reaches full development in 2.5 days.
Growth of the penultimate follicle after a blood meal is comparatively slow for the first $36 \mathrm{hr}$. Thus the penultimate follicle has accomplished $20 \%$ of its total growth by $36 \mathrm{hr}$, while the ultimate oöcyte in the same amount of time has grown $50 \%$ of the total. Thesc data were analyzed to see if the rate of growth from 0 to $36 \mathrm{hr}$ was significantly different between the ultimate and penultimate oöcytes. The slope of the line for the ultimate oöcyte was 1.29 , whereas the penultimate had a slope of 0.37 . This difference was found to be highly significant $(P<0.01)$.

To investigate the rôles of the endocrine centers of the brain and the corpora allata in controlling the postemergence growth of the follicles we used the simple techniques of decapitation and ligation. In mosquitoes the corpora allata lie in the prothorax, while the medial neurosecretory cells of the brain and their neurohaemal organ, the corpora cardiaca, lie in the head (MeOLA and LEA, 1972). Decapitation, therefore, removes the source of brain hormones from the preparation, but leaves the corpora allata present. A ligature placed at the base of the abdomen produces an isolated abdomen and removes both endocrine centers.

Decapitations $1 \mathrm{hr}$ after emergence significantly reduced $(P \leq 0.01)$ follicle growth (Fig. 2a, total height of bars). Decapitation 24 or $48 \mathrm{hr}$ after emergence had no significant effect on follicle growth. Humoral or nervous factors from the head, therefore, seem to be necessary for a short period (less than one day) after emergence.

Ligatures producing isolated abdomens gave different results. Ligation at 1 and $24 \mathrm{hr}$ after emergence significantly reduced $(P \leq 0.01)$ follicle growth (Fig. 2b). Ligation at $48 \mathrm{hr}$ also reduced follicle growth but the level of significance was lower $(P<0.05)$. Thus it appears that humoral factors from the thorax (presumably the corpora allata) are needed throughout the period of follicle growth.

It is also evident from Fig. 2 that a difference exists between decapitation and ligation in the amount of growth occurring after the operation. This information is shown in the shaded portion of the bars. When the animal is decapitated 1 or $24 \mathrm{hr}$ after emergence, the follicle continues to grow by 30 to $35 \mu$, or about $50 \%$ of the total growth. In contrast, after ligation the follicle grows only 7 to $13 \mu$. These data suggest that in the case of decapitation there is an abrupt release of head factor sufficient to maintain considerable growth in the absence of the head. Conversely, ligation results in a more sudden cessation of follicular growth, suggesting that the thoracic factor is more gradually released over a period of 2 to 3 days.

The inference that the corpora allata was the source of the humoral factor was tested by topically applying juvenile hormone in acetone to abdomens isolated at emergence. The juvenile hormone caused nearly normal growth of the follicles in the isolated abdomens (Table 2). The response of the follicle to topically applied $\mathrm{JH}$ is currently being investigated as a poss- 


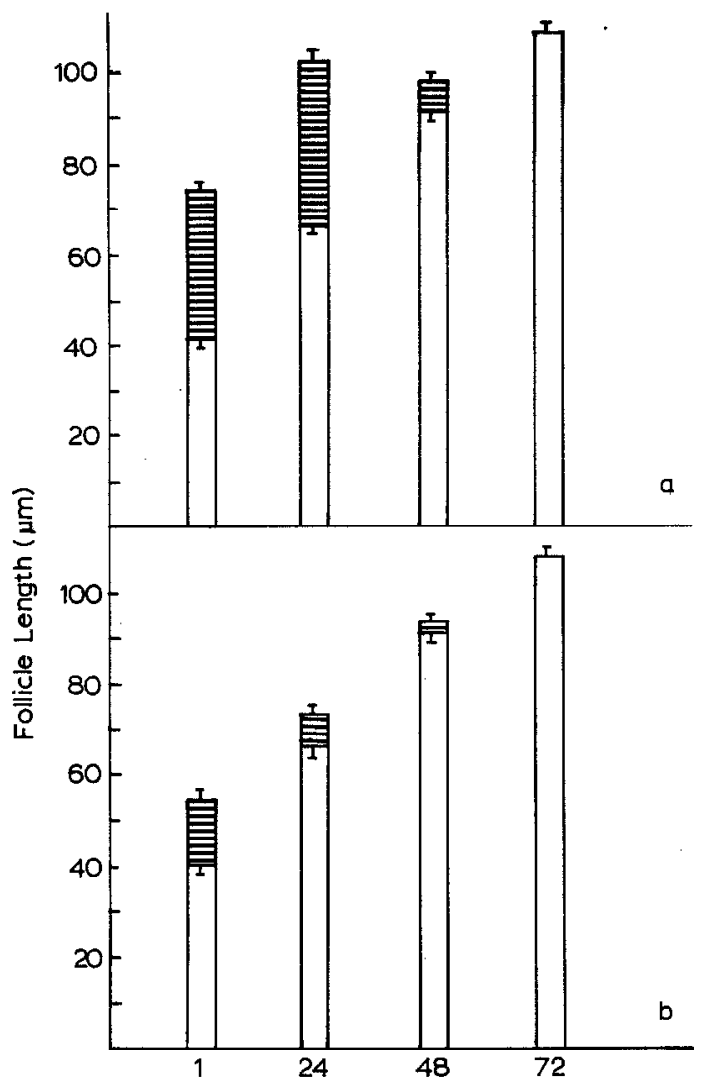

Hours After Emergence

Fig. 2. Effect of dccapitation (a), or ligations producing isolated abdomens (b), on the growth of the ultimate follicle. Operations were performed at the indicated times and follicles were measured $72 \mathrm{hr}$ after emergence. The clear portion of each bar indicates the size of the follicle at the time of the operation. The shaded portion indicates the growth of the follicle between the time of the operation and the time of dissection. In each case the standard error is indicated. The data were analyzed using Duncan's New

Multiple Range Test (STEELE and TORRIE, 1960).

ible bioassay for JH. Preliminary results indicate that it is a dependable and highly sensitive assay system.

These data confirm the results of GwADZ and SPIELMAN (1973) showing the involvement of the brain and corpora allata in the growth of the follicle to the resting stage. We have also presented data on the kinetics of follicle growth and the critical periods of hormone releasc. Regarding the latter data, it is clear that the brain hormone is released rapidly during the first day after emergence and that the juvenile hormone is released more slowly over a period of several days. The data on the kinetics of follicle growth reveals a striking difference between the rates of growth after emergence, and after a blood meal (Fig. 1). The $36 \mathrm{hr}$ lag in growth rate after a blood meal is about the amount of time that ecdysone titres are high in the mosquito (HAGEDORN et al., 1975).

Based on this correlation we suspected that ecdysone may interfere with the action of JH. Alternatively, the observed delay could more simply be due to an absence of $\mathrm{JH}$ in the haemolymph during this period. This could be due to either a lack of JH secretion, or the appearance of a specific JH esterase (SANDBURG et al., 1975). We decided to test the possibility of an interaction between $\mathrm{JH}$ and ecdysone by injecting ecdysone essentially simultaneously with the application of $\mathrm{JH}$ to isolated abdomens. When both $\mathrm{JH}$ and ecdysone were present the follicles failed to grow (Table 3 ).

These data showing that ecdysone prevents the response to JH are of interest for two reasons. First, they demonstrate once again that $\mathbf{J H}$ and ecdysone interact in ways that are presently not understood (WILlis, 1974; MASNER et al., 1975; HeRMaN and BAKER, 1976). While it is evident that such interactions could occur at a number of levels, in these experiments with isolated mosquito abdomens interactions between ecdysone and the corpora allata itself are definitely not involved.

Secondly, these data provide a basis for understanding the results of earlier experiments showing that ecdysone inhibits ovarian development in a number of different insects (ENGELMANN, 1959; RoBBINS et al., 1968; EARLE et al., 1970; WRIGHT and KAPLANIS, 1970; WRIGHT et al., 1971). Thus, on the basis of the present data we can suggest that the inhibition of egg production after treating with exogenous ecdysone was due to the inhibition of a $\mathrm{JH}$ dependent step in oögenesis. There is no doubt that $\mathbf{J H}$ does play a rôle in insect oögenesis. Exactly what this rôle is remains in doubt in most insects. It is possible that ecdysone could be used as a probe to analyze the rôle of $\mathrm{JH}$ in oögenesis.

'Table 2. Effect of juvenile hormone on growth of ovarian follicles in isolated abdomens. Means are given \pm standard error

\begin{tabular}{lc}
\hline \multicolumn{1}{c}{ Treatment } & follicle length $(\mu \mathrm{m})$ \\
\hline Unligated control & $105.3 \pm 7.6$ \\
$0.5 \mu \mathrm{l}$ acetone treated control & $42.7 \pm 2.7$ \\
$0.5 \mu$ g juvenile hormone in $0.5 \mu \mathrm{l}$ & $97.1 \pm 14$ \\
of acetone & \\
\hline
\end{tabular}


Table 3. The effect of simultaneous application of juvenile hormone and ecdysone on follicle growth in isolated abdomens. Means are given \pm standard error

\begin{tabular}{|c|c|c|}
\hline Treatment & $\mathrm{n}$ & Follicle length $(\mu \mathrm{m})$ \\
\hline $\begin{array}{l}\text { Unligated control } \\
\text { ligated control }\end{array}$ & $\begin{array}{l}20 \\
18\end{array}$ & $\begin{array}{l}76.2 \pm 1.4 \\
42.0 \pm 1.9\end{array}$ \\
\hline $\begin{array}{l}\text { ligated }+ \text { juvenile hormone } \\
\text { ligated }+ \text { acetone }\end{array}$ & $\begin{array}{l}19 \\
14\end{array}$ & $\begin{array}{l}73.6 \pm 1.8 \\
45.1 \pm 1.6\end{array}$ \\
\hline $\begin{array}{l}\text { ligated + ecdysone } \\
\text { ligated + saline }\end{array}$ & $\begin{array}{l}17 \\
17\end{array}$ & $\begin{array}{l}42.54 \pm 2.78 \\
43.19 \pm 1.47\end{array}$ \\
\hline $\begin{array}{l}\text { ligated }+ \text { juvenile hormone } \\
\text { and ecdysone }\end{array}$ & 18 & $42.37 \pm 2.29$ \\
\hline $\begin{array}{l}\text { ligated }+ \text { saline and juvenile } \\
\text { hormone }\end{array}$ & 10 & $68.22 \pm 1.55$ \\
\hline ligated + saline and acetone & 10 & $43.0 \pm 0.57$ \\
\hline
\end{tabular}

Juvenile hormone $(0.05 \mu \mathrm{g})$ was topically applied to isolated abdomens in a $0.5 \mu \mathrm{l}$ of acetone. Ecdysone $(2.5 \mu \mathrm{g})$ was injected in $0.5 \mu \mathrm{l}$ of saline before ligation.

Acknowledgements-We thank Dr. R. A. DAMon for his statistical help with data in Fig. 1. This work was supported by a grant from the National Institute of Health, No. AI 11909, and the Massachusetts Agricultural Experiment Station, project number 357. Massachusetts Agricultural Experiment Station paper number 2026.

\section{REFERENCES}

Clements A. N. (1963) The Physiology of Mosquitoes. Macmillan, New York.

DOANE W. W. (1973) The role of hormones in insect development. In Development Systems: Insects (Ed. by Counce S. J. and Waddington C. W.) pp. 291-497. Academic Press, London.

Earle N. W., Padovani I., Thompson M. J., and Robbins W. E. (1970) Inhibition of larval development and egg production in the boll weevil following ingestion of ecdysone analogues. J. econ. Ent. 63, 1064-1065.

ENGELMANN F. (1959) Uber die wirkung implantierter Prothoraxdrusen im Adulten weibchen von Leucophaea maderae. Z. vergl. Physiol. 41, 456-470.

Gwadz R. W. and Spielman A. (1973) Corpus allatum control of ovarian development in Aedes aegypti. J. In sect Physiol. 19, 1441-1448.

HAGEDORN H. H. (1974) The control of vitellogenesis in the mosquito Aedes aegypti. Am. Zool. 14, 1207-1214.

Hagedorn H. H., O'Connor J. D., Fuchs M. S., Sage B., Schlaeger D. A., and Bofm M. K. (1975) The ovary as a source of $\alpha$-ecdysone in an adult mosquito. Proc. nat. Acad. Sci.. U.S.A. 72, 3255-3259.

HERMAN W. S. and BARKER J. F. (1976) Ecdysterone antagonism, mimicry, and synergism of juvenile hormone action on the Monarch butterfly reproductive tract. $J$. Insect Physiol. 22, 643-648.

LEA A. O. (1969) Egg maturation not regulated by the corpora allata. J. Insect Physiol. 15, 537-541.

LEA A. O. (1975) Evidence that the ovaries of Musca domestica do not maintain their cyclicity by regulating the corpus allatum. J. Insect Physiol. 21, 1747-1750.

Masner P., Hangartner W., and Suchy M. (1975) Reduced titres of ecdysone following juvenile hormone treatment in the German cockroach, Blattella germanica. J. Insect Physiol. 21, 1755-1762.

Meola S. M. and LeA A. O. (1972) The ultrastructure of the corpus cardiacum of Aedes sollicitans and the histology of the cerebral neurosecretory system of mosquitoes. Gen. comp. Endocr. 18, 210-234.

Robbins W. E., Kaptanis J. N., Thompson M. J., Shortino T. J., Comen C. F., and Joynes S. C. (1968) Ecdysones and analogs. Effects on development and reproduction in insects. Science, Wash. 161, 1158-1160.

Sandburg L. L., Kramer K. J., Kezoly F. J., and Law J. H. (1975) Juvenile hormone-specific esterases in the haemolymph of the tobacco hornworm, Manduca sexta. J. Insect Physiol. 21, 873-888.

Steele R. G. D. and TorRIE J. H. (1960) Principles and Procedures of Statistics. McGraw-Hill, New York.

VARMA M. G. R. and PudneY M. (1969) The growth and serial passage of cell lines from Aedes aegypti in different media. J. med. Ent. 6, 432-439.

WILLIS J. H. (1974) Morphogenetic action of insect hormones. A. Rev. Ent. 19, 97-116.

Wright J. E., Chamberlain W. F., and Barrett C. C. (1971) Ovarian maturation in stable flies: Inhibition by 20-hydrox yecdysone. Science, Wash. 172, 1247-1248.

Wright J. E. and Kaplanis J. N. (1970) Ecdysones and ecdysone-analogs: Effects on fecundity of the stable fly, Stomoxys calcitrans. Ann. ent. Soc. Am. 63, 622-623. 